\title{
PEMBUKTIAN RUMUS BENTUK TUTUP BEDA MUNDUR BERDASARKAN DERET TAYLOR
}

\author{
WIDIA ASTUTI \\ Program Studi Matematika, \\ Fakultas Matematika dan Ilmu Pengetahuan Alam, Universitas Andalas, \\ Kampus UNAND Limau Manis Padang, Indonesia, \\ email : wastuti702@gmail.com
}

\begin{abstract}
Abstrak. Pada makalah ini dibahas pembuktian matematis dari rumus bentuk tutup beda mundur berdasarkan deret Taylor untuk menghampiri turunan pertama dari fungsi $f(x)$ di $x=x_{0}$. Pembuktian rumus bentuk tutup tersebut menggunakan sifat-sifat determinan matriks Vandermonde dan beberapa manipulasi aljabar.

Kata Kunci: Rumus beda mundur, deret Taylor, matriks Vandermonde
\end{abstract}

\section{Pendahuluan}

Banyak sekali fenomena di alam ini yang dapat dimodelkan oleh persamaan diferensial. Untuk masalah-masalah yang lebih realistis, persamaan diferensial yang dihasilkan terkadang sulit untuk dicari penyelesaian eksaknya, sehingga pendekatan numerik diperlukan untuk menyelesaikan persamaan diferensial tersebut, yaitu dengan mencari hampiran turunan fungsinya terlebih dahulu.

Salah satu metode numerik yang paling sering dan mudah digunakan dalam menghitung hampiran turunan suatu fungsi adalah metode beda hingga. Pada metode ini domain suatu fungsi dipartisi atas sejumlah titik dan rumus aproksimasi untuk turunan diperoleh dari ekspansi deret Taylor di satu atau lebih titik partisi [6]. Berdasarkan lokasi titik-titik partisi yang digunakan, metode beda hingga dibagi atas tiga jenis, yaitu beda maju (forward difference), beda mundur (backward difference), dan beda pusat (central difference). Rumus umum beda hingga untuk turunan ke- $m$ dengan ketelitian orde ke- $n$ dapat dibangkitkan dengan suatu algoritma rekursif.

Dalam tataran praktis, algoritma rekursif membutuhkan memori komputasi yang semakin besar ketika tingkatan turunan fungsi yang ingin dihampiri dan orde ketelitiannya semakin tinggi. Untuk mengatasi hal tersebut, diperlukan bentuk tutup dari rumus beda hingga agar koefisien-koefisiennya dapat ditentukan secara langsung tanpa melewati proses perhitungan secara rekursif. Adapun yang dimaksud dengan bentuk tutup di sini adalah suatu ekspresi matematika yang tidak melibatkan perhitungan secara rekursif [8]. Sebagai contoh, penjumlahan

$$
f_{n}=\sum_{i=1}^{n} i
$$


dapat dihitung secara rekursif, artinya untuk menghitung $f_{n}$ perlu diketahui dulu $f_{n-1}$ dan seterusnya. Namun, dengan menggunakan bentuk tutup, penjumlahan di atas dapat dinyatakan dalam bentuk

$$
f_{n}=\frac{n(n+1)}{2},
$$

yang menjadi lebih sederhana perhitungannya, karena langsung dapat dihitung untuk setiap $n$ (tanpa harus tahu dulu nilai $f_{n-1}$ ). Dalam makalah ini akan dibahas pembuktian rumus bentuk tutup beda mundur berdasarkan deret Taylor yang dikembangkan oleh Khan dan Ohba dalam referensi [4]. Pembuktian tersebut dibatasi untuk turunan pertama dari fungsi satu variabel.

\section{Landasan Teori}

\subsection{Deret Taylor}

Teorema 2.1. [2] (Teorema Taylor) Misalkan $n \in \mathbb{N}, I=[a, b]$, dan $f: I \rightarrow \mathbb{R}$ sedemikian sehingga $f^{\prime}, f^{\prime \prime}, \cdots, f^{(n)}$ kontinu di I dan $f^{(n+1)}$ ada pada $(a, b)$. Jika $x_{0} \in I$, maka untuk setiap $x$ di I terdapat suatu titik c di antara $x$ dan $x_{0}$ sedemikian sehingga

$$
\begin{aligned}
f(x)= & f\left(x_{0}\right)+f^{\prime}\left(x_{0}\right)\left(x-x_{0}\right)+\frac{f^{\prime \prime}\left(x_{0}\right)}{2 !}\left(x-x_{0}\right)^{2}+\cdots \\
& +\frac{f^{(n)}\left(x_{0}\right)}{n !}\left(x-x_{0}\right)^{n}+R_{n}(x),
\end{aligned}
$$

dimana

$$
R_{n}(x)=\frac{f^{(n+1)}(c)}{(n+1) !}\left(x-x_{0}\right)^{n+1} .
$$

Jika fungsi $f$ memiliki turunan sampai tak-hingga kali di titik $x_{0}$ dalam $\mathbb{R}$, persamaan (2.1) dapat ditulis

$$
f(x)=\sum_{n=0}^{\infty} \frac{f^{(n)}\left(x_{0}\right)}{n !}\left(x-x_{0}\right)^{n} .
$$

Persamaan (2.3) dikenal sebagai deret Taylor untuk $f(x)$ di $x \approx x_{0}$. Jika ditulis $x=x_{0}+h$ dan kemudian ganti kembali $x_{0}$ dengan $x$, persamaan (2.1) menjadi

$$
f(x+h)=f(x)+f^{\prime}(x) h+\frac{f^{\prime \prime}(x)}{2 !} h^{2}+\cdots+\frac{f^{(n)}(x)}{n !} h^{n}+R_{n}(x),
$$

dimana

$$
R_{n}(x)=\frac{f^{(n+1)}(c)}{(n+1) !} h^{n+1} .
$$

\subsection{Determinan Matriks}

Teorema 2.2. [1] Misalkan A adalah sebarang matriks $n \times n$.

(i) Jika $A^{\prime}$ adalah matriks yang dihasilkan bila baris tunggal atau kolom tunggal matriks $A$ dikalikan oleh konstanta $k$, maka $\operatorname{det}\left(A^{\prime}\right)=k \operatorname{det}(A)$. 
(ii) Jika $A^{\prime}$ adalah matriks yang dihasilkan bila kelipatan satu baris matriks $A$ ditambahkan pada baris lain atau kelipatan satu kolom matriks $A$ ditambahkan pada kolom lain, maka $\operatorname{det}\left(A^{\prime}\right)=\operatorname{det}(A)$.

\subsection{Determinan Matriks Vandermonde}

Definisi 2.3. [7] Matriks $V$ berukuran $M \times N$ yang berbentuk

$$
V_{M \times N}=\left[\begin{array}{ccccc}
1 & \lambda_{1} & \lambda_{1}^{2} & \cdots & \lambda_{1}^{N-1} \\
1 & \lambda_{2} & \lambda_{2}^{2} & \cdots & \lambda_{2}^{N-1} \\
1 & \lambda_{3} & \lambda_{3}^{2} & \cdots & \lambda_{3}^{N-1} \\
\vdots & \vdots & \vdots & \ddots & \vdots \\
1 & \lambda_{M} & \lambda_{M}^{2} & \cdots & \lambda_{M}^{N-1}
\end{array}\right]
$$

dimana $\lambda_{i} \neq \lambda_{j}$ untuk setiap $i \neq j$ disebut matriks Vandermonde.

Teorema 2.4. [7] Determinan matriks Vandermonde yang berukuran $N \times N$ diberikan oleh

$$
\left|V_{N \times N}\right|=\left|\begin{array}{ccccc}
1 & \lambda_{1} & \lambda_{1}^{2} & \cdots & \lambda_{1}^{N-1} \\
1 & \lambda_{2} & \lambda_{2}^{2} & \cdots & \lambda_{2}^{N-1} \\
1 & \lambda_{3} & \lambda_{3}^{2} & \cdots & \lambda_{3}^{N-1} \\
\vdots & \vdots & \vdots & \ddots & \vdots \\
1 & \lambda_{n} & \lambda_{n}^{2} & \cdots & \lambda_{N}^{N-1}
\end{array}\right|=\prod_{\substack{1<i \leq N \\
1 \leq j<N \\
j<i}}\left(\lambda_{i}-\lambda_{j}\right) .
$$

Berdasarkan Teorema (2.4) diperoleh akibat berikut.

Akibat 2.5. [7] Nilai determinan dari matriks Vandermonde $N \times N$ yang secara khusus berbentuk

$$
\left[\begin{array}{ccccc}
1 & 1 & 1 & \cdots & 1 \\
1 & 2 & 2^{2} & \cdots & 2^{N-1} \\
1 & 3 & 3^{2} & \cdots & 3^{N-1} \\
\vdots & \vdots & \vdots & \ddots & \vdots \\
1 & N & N^{2} & \cdots & N^{N-1}
\end{array}\right]
$$

diberikan oleh

$$
\alpha_{N}=\prod_{\substack{1<i \leq N \\ 1 \leq j<N \\ j<i}}(i-j)=\prod_{i=1}^{N}(N-i) !
$$

Selanjutnya pandang determinan dari matriks $(N-1) \times(N-1)$ yang diperoleh dengan menghapus baris ke- $k$ dan kolom terakhir dari matriks (2.8), yakni diberikan 
oleh

$$
\beta_{N-1, k}=\left|\begin{array}{ccccc}
1 & 1 & 1 & \cdots & 1 \\
1 & 2 & 2^{2} & \cdots & 2^{N-2} \\
\vdots & \vdots & \vdots & \ddots & \vdots \\
1 & k-1 & (k-1)^{2} & \cdots & (k-1)^{N-2} \\
1 & k+1 & (k+1)^{2} & \cdots & (k+1)^{N-2} \\
\vdots & \vdots & \vdots & \ddots & \vdots \\
1 & N & N^{2} & \cdots & N^{N-2}
\end{array}\right| .
$$

Karena ekspresi di atas juga merupakan matriks Vandermonde, maka determinannya diberikan oleh $\alpha_{N}$ tetapi untuk $i \neq k$ dan $j \neq k$. Dengan demikian berlaku

$$
\begin{aligned}
\beta_{N-1, k} & =\prod_{\substack{1<i \leq N, i \neq k \\
1 \leq j<N, j \neq k \\
j<i}}(i-j) \\
& =\frac{1}{(k-1) !(N-k) !} \prod_{i=1}^{N}(N-i) !
\end{aligned}
$$

\section{Pembahasan}

\subsection{Rumus Bentuk Tutup Beda Mundur}

Dalam [5], Khan dkk telah mengembangkan rumus bentuk tutup beda hingga berdasarkan deret Taylor. Untuk hampiran turunan pertama suatu fungsi $f(x)$ di titik $x=x_{0}$, bentuk tutupnya diberikan oleh

$$
f_{0}^{\prime} \approx \frac{1}{T} \sum_{k} g_{k} f_{k},
$$

dimana $T$ adalah lebar selang partisi dari domain sedangkan koefisien $g_{k}$ dan iterator $k$ didefinisikan berdasarkan orde ketelitian dan jenis beda hingga. Untuk aproksimasi beda mundur, iterator $k$ diuraikan atas $k=-N,-N+1, \cdots,-1,0$, dimana $N$ adalah orde ketelitian, dan koefisien $g_{k}$ didefinisikan oleh

$$
g_{k}= \begin{cases}\sum_{j=1}^{N} \frac{1}{j} & k=0, \\ \frac{(-1)^{k} N !}{-k(N+k) !(-k) !} & k=-N,-N+1, \cdots,-1 .\end{cases}
$$

\subsection{Pembuktian Rumus Bentuk Tutup Beda Mundur}

Pandang kembali deret Taylor $(2.3)$ untuk $f(x)$ di $x \approx x_{0}$ yang diberikan oleh

$$
\begin{aligned}
f(x) & =f\left(x_{0}\right)+\left(x-x_{0}\right) f^{\prime}\left(x_{0}\right)+\frac{\left(x-x_{0}\right)^{2}}{2} f^{\prime \prime}\left(x_{0}\right) \\
& +\frac{\left(x-x_{0}\right)^{3}}{3 !} f^{\prime \prime \prime}\left(x_{0}\right)+\cdots
\end{aligned}
$$

Jika $x$ dipartisi sebanyak $N$ selang dengan lebar $\Delta x=T$ dimana $T \in \mathbb{R}^{+}$maka diperoleh titik-titik partisi

$$
x_{k}=x_{0}-k T, k=1,2, \cdots, N .
$$


Dengan demikian deret Taylor (3.2) pada saat $x=x_{k}$ adalah

$$
f_{k}-f_{0}=(-k T) f_{0}^{(1)}+\frac{(-k T)^{2}}{2 !} f_{0}^{(2)}+\frac{(-k T)^{3}}{3 !} f_{0}^{(3)}+\cdots
$$

dimana $f_{0}=f\left(x_{0}\right), f_{k}=f\left(x_{k}\right)$ dan $f_{0}^{(m)}=f^{(m)}\left(x_{0}\right)$ dengan $m$ menyatakan turunan ke- $m$.

Persamaan (3.3) yang dipotong sampai suku ke- $N$ dapat ditulis dalam bentuk matriks sebagai

$$
\mathbf{f} \approx A \mathbf{d}
$$

dimana

$$
\begin{aligned}
& \mathbf{d}=\left[\begin{array}{lllll}
f_{0}^{(1)} & f_{0}^{(2)} & f_{0}^{(3)} & \cdots & f_{0}^{(N)}
\end{array}\right]^{T}, \\
& \mathbf{f}=\left[f_{1}-f_{0} f_{2}-f_{0} \cdots f_{N}-f_{0}\right]^{T}, \\
& A=\left[\begin{array}{cccc}
-T & (T)^{2} / 2 ! & \cdots & (-T)^{N} / N ! \\
-2 T & (2 T)^{2} / 2 ! & \cdots & (-2 T)^{N} / N ! \\
\vdots & \vdots & \ddots & \vdots \\
-N T & (N T)^{2} / 2 ! & \cdots & (-N T)^{N} / N !
\end{array}\right]
\end{aligned}
$$

Dengan menggunakan aturan Cramer, nilai dari $f_{0}^{(1)}$ diberikan oleh

$$
f_{0}^{(1)} \approx \frac{|B|}{|A|}
$$

dimana $B$ diperoleh dengan mengganti kolom pertama matriks $A$ dengan vektor kolom $\mathbf{f}$, yaitu

$$
B=\left[\begin{array}{cccc}
f_{1}-f_{0} & T^{2} / 2 ! & \cdots & (-T)^{N} / N ! \\
f_{2}-f_{0} & (2 T)^{2} / 2 ! & \cdots & (-2 T)^{N} / N ! \\
\vdots & \vdots & \ddots & \vdots \\
f_{N}-f_{0} & (N T)^{2} / 2 ! & \cdots & (-N T)^{N} / N !
\end{array}\right]
$$

Berdasarkan sifat determinan pada Teorema (2.2)[i], persamaan (3.4) dapat ditulis menjadi

$$
f_{0}^{(1)} \approx \frac{\left(T^{2}\right)(-T)^{3} \cdots(-T)^{N}}{(-T)\left(T^{2}\right) \cdots(-T)^{N}} \frac{|B|_{T=1}}{|A|_{T=1}}=-\frac{1}{T} \frac{|B|_{T=1}}{|A|_{T=1}} .
$$

Selanjutnya dengan mengeluarkan faktor kelipatan dari setiap baris dan kolom pada $|A|_{T=1}$, diperoleh

$$
|A|_{T=1}=\frac{(2)(3) \cdots(N)}{(2 !)(3 !) \cdots(N !)}\left|\begin{array}{cccc}
1 & 1 & \cdots & 1 \\
1 & 2 & \cdots & 2^{N-1} \\
\vdots & \vdots & \ddots & \vdots \\
1 & N & \cdots & N^{N-1}
\end{array}\right|
$$


Perhatikan bahwa determinan matriks yang muncul pada persamaan (3.6) merupakan determinan matriks Vandermonde. Berdasarkan Akibat 2.5, maka berlaku

$$
\begin{aligned}
|A|_{T=1} & =\frac{(2)(3) \cdots(N)}{(2 !)(3 !) \cdots(N !)}\left|\begin{array}{cccc}
1 & 1 & \cdots & 1 \\
1 & 2 & \cdots & 2^{N-1} \\
\vdots & \vdots & \ddots & \vdots \\
1 & N & \cdots & N^{N-1}
\end{array}\right| \\
& =\frac{\alpha_{N}}{(2 !)(3 !) \cdots((N-1) !)}=1
\end{aligned}
$$

dimana $\alpha_{N}$ diberikan oleh persamaan (2.9). Dengan demikian persamaan (3.4) menjadi

$$
f_{0}^{(1)} \approx-\frac{1}{T}|B|_{T=1}
$$

yang dapat disederhanakan menjadi

$$
f_{0}^{(1)} \approx \frac{1}{T}\left(\sum_{k=1}^{N} g_{k} f_{k}-\sum_{k=1}^{N} g_{k} f_{0}\right) .
$$

dimana $g_{k}$ untuk $k=1,2, \cdots, N$ adalah kofaktor dari $[B]_{T=1}$ yang berkorespondensi dengan elemen ke- $k$ dari kolom pertama, yaitu diberikan oleh

$$
g_{k}=(-1)^{k}\left|\begin{array}{cccc}
1 / 2 ! & 1 / 3 ! & \cdots & 1 / N ! \\
2^{2} / 2 ! & 2^{3} / 3 ! & \cdots & 2^{N} / N ! \\
\vdots & \vdots & \ddots & \vdots \\
(k-1)^{2} / 2 ! & (k-1)^{3} / 3 ! & \cdots & (k-1)^{N} / N ! \\
(k+1)^{2} / 2 ! & (k+1)^{3} / 3 ! & \cdots & (k+1)^{N} / N ! \\
\vdots & \vdots & \ddots & \vdots \\
N^{2} / 2 ! & N^{3} / 3 ! & \cdots & N^{N} / N !
\end{array}\right|
$$

Dengan mendefinisikan

$$
g_{0}=-\sum_{k=1}^{N} g_{k}
$$

maka persamaan (3.8) dapat ditulis

$$
f_{0}^{(1)} \approx \frac{1}{T} \sum_{k=0}^{N} g_{k} f_{k} .
$$

Dengan mengeluarkan faktor kelipatan dari setiap baris dan kolom pada $g_{k}$, diperoleh

$$
g_{k}=(-1)^{k} \frac{\left(2^{2}\right)\left(3^{2}\right) \cdots\left(N^{2}\right)}{(2 !)(3 !) \cdots(N !)}\left|\begin{array}{cccc}
1 & 1 & \cdots & 1 \\
1 & 2 & \cdots & 2^{N-2} \\
\vdots & \vdots & \ddots & \vdots \\
1 & (k-1) & \cdots & (k-1)^{N-2} \\
1 & (k+1) & \cdots & (k+1)^{N-2} \\
\vdots & \vdots & \ddots & \vdots \\
1 & N & \cdots & N^{N-2}
\end{array}\right| .
$$


Perhatikan bahwa determinan matriks yang muncul pada persamaan (3.11) sama dengan determinan matriks pada persamaan (2.10) dengan nilainya diberikan oleh persamaan (2.11). Jadi

$$
\begin{aligned}
g_{k} & =(-1)^{k} \frac{\left(2^{2}\right)\left(3^{2}\right) \cdots\left(N^{2}\right)}{\left(k^{2}\right)(2 !)(3 !) \cdots(N !)} \frac{(N-1) !(N-2) ! \cdots(3) !(2) !(1) !}{(k-1) !(N-k) !} \\
& =\frac{(-1)^{k} N !}{k(N-k) ! k !}
\end{aligned}
$$

dengan $k=1,2, \cdots, N$.

Selanjutnya dari persamaan (3.9) diperoleh

$$
g_{0}=-\sum_{k=1}^{N} g_{k}=\sum_{k=1}^{N} \frac{(-1)^{k+1} N !}{k(N-k) ! k !} .
$$

Pandang terlebih dahulu fungsi

$$
y(x)=-\left(\frac{(1-x)^{N}-1}{x}\right)
$$

yang dapat diuraikan dengan menggunakan ekspansi binomial dari $(1-x)^{N}$ sehingga diperoleh

$$
\begin{aligned}
y(x) & =-\frac{1}{x}\left(\left(1+\sum_{k=1}^{N} \frac{(-1)^{k} N !}{k(N-k) !} x^{k}\right)-1\right) \\
& =\sum_{k=1}^{N} \frac{(-1)^{k+1} N !}{k !(N-k) !} x^{k-1} .
\end{aligned}
$$

Perhatikan bahwa

$$
\begin{aligned}
\int_{0}^{1} y(x) d x & =\int_{0}^{1} \sum_{k=1}^{N} \frac{(-1)^{k+1} N !}{k !(N-k) !} x^{k-1} d x \\
& =\sum_{k=1}^{N} \frac{(-1)^{k+1} N !}{k(N-k) ! k !} .
\end{aligned}
$$

Dari persamaan (3.13) dan (3.14) dapat ditulis

$$
g_{0}=\int_{0}^{1} y(x) d x .
$$

Fungsi $y(x)$ juga dapat diuraikan dengan manipulasi aljabar sebagai berikut:

$$
\begin{aligned}
y(x) & =-\left(\frac{1}{x}((1-x)-1)\left((1-x)^{N-1}+(1-x)^{N-2}+\cdots+1\right)\right) \\
& =\sum_{k=1}^{N}(1-x)^{k-1}
\end{aligned}
$$


yang dapat digunakan pada persamaan (3.15) untuk mendapatkan

$$
g_{0}=\int_{0}^{1} y(x) d x=\int_{0}^{1} \sum_{k=1}^{N}(1-x)^{k-1} d x=\sum_{k=1}^{N} \frac{1}{k} .
$$

Dengan demikian, dari persamaan (3.12) dan (3.16) diperoleh

$$
g_{k}= \begin{cases}\sum_{j=1}^{N} \frac{1}{j} & k=0, \\ \frac{(-1)^{k} N !}{k(N-k) ! k !} & k=1,2, \cdots, N,\end{cases}
$$

yang membuktikan rumus koefisien beda mundur (??) setelah mengganti $k$ dengan $-k$.

\section{Kesimpulan dan Saran}

Pada makalah ini telah dijelaskan mengenai pembuktian rumus bentuk tutup beda mundur berdasarkan deret Taylor untuk menghampiri turunan pertama dari fungsi $f(x)$ di $x=x_{0}$. Rumus bentuk tutup beda mundur tersebut diberikan oleh

$$
f_{0}^{\prime} \approx \frac{1}{T} \sum_{k=0}^{N} g_{k} f_{k}
$$

dimana $f_{k}=f\left(x_{k}\right), N$ menyatakan orde ketelitian, dan

$$
g_{k}= \begin{cases}\sum_{j=1}^{N} \frac{1}{j} & k=0, \\ \frac{(-1)^{k} N !}{k(N-k) ! k !} & k=1,2, \cdots, N .\end{cases}
$$

Pembuktian bentuk tutup tersebut menggunakan sifat-sifat determinan matriks Vandermonde dan beberapa manipulasi aljabar.

Untuk penelitian selanjutnya, penulis menyarankan untuk membuat pemrograman numerik dalam menyelesaikan persamaan diferensial dengan menggunakan metode beda mundur yang koefisien-koefisiennya diberikan oleh rumus bentuk tutup (3.2).

\section{Ucapan Terima kasih}

Penulis mengucapkan terima kasih kepada Bapak Mahdhivan Syafwan, Bapak Bukti Ginting, Ibu Lyra Yulianti, Ibu Nova Noliza Bakar dan Ibu Riri Lestari yang telah memberikan masukan dan saran sehingga makalah ini dapat diselesaikan dengan baik.

\section{Daftar Pustaka}

[1] Anton, H. 2004. Aljabar Linier Elementer. Edisi kedelapan. Erlangga, Jakarta.

[2] Bartle, Robert G., dan Donald R. Sherbert. 2011. Introduction to Real Analysis. Edisi ke-4. John Wiley and Son, Urban-Champaign. 
[3] Bengt, Fornberg. 1988. Generation of Finite Difference Formulas on Arbitrarily Spaced Grids. Mathematics of Computation. 51 : 184.

[4] I.R. Khan, dan R. Ohba. 1999. Closed form expressions for the finite difference approximations of first and higher derivatives based on Taylor series. $J$. Comput. Appl. Math. 107: $179-193$.

[5] I. R. Khan, R. Ohba, dan N. Hozumi. 2003. Mathematical proof of closed form expressions for finite difference approximations based on Taylor series. $J$. Comput. Appl. Math. 150: 303 - 309.

[6] Mathews, John H., K.D. Fink. 1992. Numerical Methods for Computer Science, Engineering, and Mathematics. Edisi ke-2. Prentice-Hall, Englewood Cliffs.

[7] Meyer, Carl D. 2000. Matrix Analysis and Applied Linear Algebra. SIAM. Philadelphia.

[8] Timothy Y. Chow. 1999. What is a Closed-Form Number. The American Mathematical Monthly. 106 : 440 - 448. 